\title{
INEFICACIA DE LA SUSPENSIÓN DE LA EJECUCIÓN DE LA PENA EN LA RESOCIALIZACIÓN DEL CONDENADO
}

\author{
INEFFICIENCY OF THE SUSPENSION OF THE EXECUTION OF THE PENALTY \\ IN THE RESOCIALIZATION OF THE CONDEMNED
}

Ana María Cerdeña del Águila ${ }^{1}$

Aceptado: 27/05/2020

Publicado online: 14/12/2020

\begin{abstract}
RESUMEN
Este estudio se orientó a analizar en qué medida la aplicación ineficaz de la suspensión de la ejecución de la pena establecida en el Código Penal incide en la resocialización del condenado. Una investigación de tipo aplicada, diseño observacional, transversal, cuyo método lógico inductivo-deductivo. Para el levantamiento de la información se aplicó el cuestionario, la entrevista y la ficha de análisis como instrumentos de medición; los cuales permitieron recoger información, y medir las variables de estudio. La muestra estuvo conformada por 165 profesionales de derecho y 69 sentencias sobre la suspensión de la ejecución de la pena. Los resultados obtenidos permitieron establecer que: Probablemente la ineficaz aplicación de la suspensión de la ejecución de la pena establecida en el Código Penal incide en la resocialización del condenado, Tacna 20152018.
\end{abstract}

Palabras Clave: Suspensión, ejecución, pena, resocialización, condenado, reeducación, rehabilitación, reincorporación.

\begin{abstract}
This study was aimed at analysing the extent to which the ineffective application of the suspension of the execution of the sentence established in the Criminal Code affects the resocialization of the convicted person. An investigation of applied type, observational, transversal design, whose logical inductive-deductive method. The questionnaire, the interview and the analysis form were used as measurement instruments to gather information and measure the study variables. The sample was made up of 165 law professionals and 69 sentences on suspended sentences. The results obtained made it possible to establish that: Probably the ineffective application of the suspension of the execution of the sentence established in the Criminal Code affects the re-socialization of the convicted person, Tacna 2015-2018.
\end{abstract}

Keywords: Suspension, execution, penalty, resocialization, convicted, reeducation, rehabilitation, reinstatement.

\footnotetext{
1 Doctor en Derecho Penal y Política Criminal, Magíster en Derecho Constitucional, Secretaria de Sala en la Corte Superior de
} Justicia de Tacna. acerdena@pi.gob.pe. (1) 


\section{INTRODUCCIÓN}

Un hecho delictuoso traerá como consecuencia la imposición de una pena para el que infringe la norma penal. La pena se manifiesta privando o restringiendo los derechos del condenado, y así lo señaló el juez cuando dictó la sentencia. El actual "Código Penal" incorpora el catálogo de sanciones modernas, que incluye penas de prisión reducidas y nuevas sanciones penales, que se caracterizan por eliminar el uso de las cárceles para los delitos más graves, conforme al artículo 28 del Código Penal de 1991 (p. 74), las penas aplicables a los autores de un hecho punible son de cuatro clases: $1^{\circ}$ Las penas privativas de libertad, que puede ser temporal o de cadena perpetua; $2^{\circ}$ Las penas restrictivas de libertad; $3^{\circ}$ Las penas limitativas de derechos; $y, 4^{\circ}$ La pena de multa.

Al respecto el Código Penal en el artículo IX del Título Preliminar (p. 47.) señala que la pena tiene función preventiva, protectora y resocializadora. El trabajo desarrollado se basa en los delitos que son sancionables con pena privativa de libertad suspendida, lo cual no estaría encaminada a la resocialización del delincuente, debido a que no cumple su finalidad. El problema surge es que la pena privativa de libertad suspendida resulta ineficaz; dado que no se cumple con la función preventiva, protectora y resocializadora que la legislación ha previsto en el artículo IX del Título Preliminar del Código Penal. (Garcia Cavero, Titulo IX Fines de la Pena, 2005)

Si la pena privativa de libertad suspendida, no surte sus efectos sociales, se considera obsoleta; por lo tanto, debe proceder a su derogación. También se puede verificar que la pena privativa de libertad suspendida no cumple su finalidad resocializadora, es decir, los condenados no acuden a las instalaciones del Poder Judicial a registrar su firma de manera mensual, ni a justificar documentariamente sus actividades, tampoco cumple con el pago de la reparación civil, y peor aún, no informan respecto a su cambio de domicilio, ni solicitan permiso para ausentarse del lugar de su residencia; entre otras reglas de conducta que impone en Juez; lo cual constituye un latente y flagrante problema para la vigencia y aplicación del Derecho Penal.

Por estas consideraciones surge la pregunta ¿En qué medida la ineficaz aplicación de la suspensión de la ejecución de la pena establecida en el Código Penal incide en la resocialización del condenado?

La suspensión de la ejecución de las penas privativas de libertad en el Código penal español (Franco, 2017): A pesar de todas estas reformas, el tribunal aún enfrenta cuestiones controvertidas en su aplicación. La ley actual sigue siendo vaga e inexacta, lo que hace que la gente cuestione su aplicabilidad práctica y debe ser resuelta por el tribunal. En esta realidad, la resocialización implica hacinamiento en las cárceles, que a su vez está plagado de violencia, corrupción y un ambiente desigual, restringiendo la provisión y acceso a los programas de resocialización, lo que dificulta la recuperación individual. Al observar cuántos de los presos que cometieron reincidencia regresaron a la prisión, fallaron la prueba de fuego diseñada para lograr este objetivo. (Hernández, 2015).

Según el análisis, el proceso de resocialización de los presos condenados por robo grave en el distrito judicial de Lima Norte de 2013 a 2017 tiene un impacto negativo. En este sentido, no se ha cumplido el artículo II del título del Código Penal. En dicho Código estipula las posibilidades de capacitar al recluso para que reciba educación, rehabilitación y reinserción social para lograr su resocialización; como se señaló, la gran mayoría de los presos condenados por delitos grave no se resocializó debido al tratamiento penitenciario. Además, las leyes que los rigen no pueden satisfacer sus necesidades ni generar falsas expectativas, gestión penitenciaria inadecuada y porque no se respetan la mayoría de sus derechos (Gonzales, 2018). El proceso de resocialización y rehabilitación de aquellos que tienen la oportunidad de recibir una pena privativa suspendida se 
contempla de acuerdo a las normas, con la finalidad que sea esta una oportunidad para que los condenados a penas privativas de libertad suspendidas se reinserten al grupo familiar, así como a la sociedad; sin embargo, en la práctica del día a día se evidencia una realidad distinta, siendo que estos mismos vuelven a delinquir no aprovechando esta oportunidad de beneficio (Briceño, 2018). Las consecuencias que se podría producir cuando una sentencia en primera instancia en el proceso penal militar policial es impugnada mediante apelación, debido al efecto suspensivo de la ejecución de la pena privativa de libertad que sufre de manera automática con el sólo hecho de presentar el recurso impugnatorio (Arroyo, 2017).

Se concluye lo siguiente; Con la regulación del artículo $464^{\circ}$ del Código Penal Militar Policial se abre la posibilidad de que existan consecuencias que impedirían continuar con el proceso como por ejemplo los peligros procesales tales como el peligro de fuga, el incumplimiento de la sentencia e incluso la reincidencia delictiva por lo que es necesario implementar un mecanismo mediante el cual se asegure el acatamiento de la sentencia en caso de ser confirmada en el proceso penal militar policial, para así poder evitar los peligros de fuga que se pueden dar por causa intencional del imputado.

La sanción por la prestación de servicios a la comunidad incluye la obligación de realizar trabajo gratuito en instituciones asistenciales y obras públicas. Esto es una sanción, no un trabajo normal. También se da en lugares que no lucrativos, teniendo en cuenta el talento del condenado, el horario no interrumpirá su trabajo habitual. La restricción de vacaciones es que los condenados están obligados a permanecer en lugares organizados con fines educativos; están orientados a la rehabilitación y la ventaja es que pueden recibir capacitación en lugares apropiados y permanecer en instituciones de 10 a 16 horas cada fin de semana. (Chávez, 2017). La cuestión de la forma en que se suspende la ejecución de la pena de detención incide en el objetivo de la prevención activa global, porque en algunos casos la suspensión de la ejecución no cumple con los requisitos de la Ley Penal. En la mayoría de las sentencias, la ejecución de la sentencia no debe suspenderse, lo que afectará gravemente la comunicación, la confianza y los efectos educativos de la sentencia. (Merino, 2014).

\section{OBJETIVOS}

Analizar en qué medida las ineficaces medidas impuestas ante el incumplimiento de la suspensión de la ejecución de la pena establecida en el Código Penal inciden en la resocialización del condenado.

\section{METODOLOGÍA DE LA INVESTIGACIÓN}

Las variables estudiadas fueron: a) Aplicación de la suspensión de la ejecución de la pena: (Tiempo de condena de pena privativa de la libertad, Modalidad del hecho punible y Motivación de la conducta del condenado); Reglas de conducta (Cumplimiento de obligaciones, Cumplimiento de prohibiciones y Control de cumplimiento) y Medidas impuestas ante el cumplimiento (Amonestación, Prórroga y Revocatoria). b) Resocialización del condenado: Reeducación (Medidas resocializadoras implementadas, Programas aplicados); Rehabilitación (Actividades rehabilitadoras, Tipo de ocupación y Nivel de rehabilitación) y Reincorporación (Corrección de conducta, Reincidencia)

Enfoque mixto de la investigación, en las técnicas e instrumentos usados, se aplicó el enfoque cuantitativo, usa la recolección de datos para probar hipótesis, con base en la medición numérica y el análisis estadístico, para establecer patrones de comportamiento y probar teorías, que para el 
caso de estudio fue la aplicación del cuestionario de escala nominal; y los resultados sobre las sentencias de suspensión de ejecución de la pena; y el enfoque cualitativo utiliza la recolección de datos sin medición numérica para descubrir o afinar preguntas de investigación en el proceso de interpretación, aplicándose para ello la entrevista. (Hernández \& Fernández, 2014, pág. 534).

El presente trabajo de investigación, desde la perspectiva de su objetivo es una investigación aplicada, toda vez que está orientada a la aplicación de los conocimientos teórico-científicos, dirigidos a la solución del problema, confrontando la teoría con la realidad, con el objeto de lograr un nuevo conocimiento (Villabella, 2015, pág. 921) El Diseño de investigación fue observacional de corte transversal, en tanto no hubo manipulación de variables, sino que los datos fueron recogidos después de ocurrido el hecho; y está referido al período 2015-2018, dado que el estudio comprende los casos sobre la suspensión de la ejecución de la pena y la resocialización del condenado. de Tacna-20152018.

La población de estudio la comprenden los profesionales del derecho en materia penal de Tacna; y los expedientes judiciales sobre la suspensión de la ejecución de la pena. Para la determinación de la muestra se aplicó el muestreo probabilístico, aleatorio, estratificado, porque la selección se realizó bajo el propio criterio de la investigadora, en cuanto a la selección de los profesionales del derecho (abogados, jueces y fiscales) y los casos sobre suspensión de ejecución de la pena. Estratificación de la muestra fue la siguiente: 2(7 jueces), 5(16 fiscales penales), 158(265 abogados), 69(88 expedientes), siendo en total 234 personas evaluadas de 376 que comprende la población total. Para la recolección de datos se recurrió a la aplicación de los instrumentos de medición a la muestra determinada, aplicados bajo las técnicas respectivas. Como técnicas para el desarrollo de la investigación se utilizó la encuesta, la entrevista y el análisis documental.

Los instrumentos de medición que se aplicaron fueron: el cuestionario con preguntas dicotómicas aplicadas con escala nominal, la cédula de entrevista (preguntas abiertas) y la ficha de análisis documental (alternativas múltiples). Para la aplicación de los instrumentos de medición se realizó la validación mediante juicio de expertos, los cuales fueron Doctores en derecho y conocedores de metodología de la investigación.

\section{RESULTADOS}

Todos los jueces señalan que sí se cumple con motivar suficientemente la aplicación de la suspensión de la ejecución de la pena. El $80 \%$ de los fiscales encuestados señalan que no se cumple; y el $20 \%$ señala lo contrario. El $85 \%$ de los abogados encuestados señalan que no se cumple y el $15 \%$ señala lo contrario. Los resultados nos permiten determinar que no se cumple con motivar suficientemente la aplicación de la suspensión de la ejecución de la pena.

En su totalidad los jueces señalan que las reglas de conducta impuesta en las medidas suspensión de la ejecución de la pena no son adecuadas para garantizar la resocialización del condenado. El $80 \%$ de los fiscales encuestados señalan que las reglas no son adecuadas para garantizar la resocialización del condenado; y el $20 \%$ señala lo contrario. El $88 \%$ de los abogados encuestados señalan que las reglas no son adecuadas para garantizar la resocialización del condenado; y, el $12 \%$ señala lo contrario. Los resultados nos permiten determinar que las reglas de conducta impuesta en las medidas suspensión de la ejecución de la pena no son adecuadas para garantizar la resocialización del condenado.

Todos los jueces encuestados señalan que no se cumple con implementar medidas resocializadoras y rehabilitadoras para garantizar la resocialización del condenado. El $100 \%$ de los fiscales encuestados señalan que no se cumple. El $89 \%$ de los abogados encuestados señalan que no se cumple $y$, el $11 \%$ dice lo contrario. Los resultados nos permiten determinar que no se 
cumple con implementar medidas resocializadoras y rehabilitadoras para garantizar la resocialización del condenado.

Los jueces en su totalidad señalan que, en los casos de suspensión de la ejecución de la pena, los condenados no corrigen su conducta. El $100 \%$ de los fiscales encuestados señalan que, los condenados no corrigen su conducta. El $82 \%$ de los abogados encuestados señalan que, los condenados no corrigen su conducta; y, el $18 \%$ dice lo contrario. Los resultados nos permiten determinar que, en los casos de suspensión de la ejecución de la pena, los condenados no corrigen su conducta.

Tabla 1

Respuestas al cuestionario aplicado a los profesionales del derecho

\begin{tabular}{|c|c|c|c|c|c|c|}
\hline \multirow[t]{3}{*}{ Respuesta } & \multicolumn{6}{|c|}{ Muestra } \\
\hline & \multicolumn{2}{|c|}{ Jueces } & \multicolumn{2}{|c|}{ Fiscales } & \multicolumn{2}{|c|}{ Abogados } \\
\hline & $f$ & $\%$ & f & $\%$ & $\mathrm{f}$ & $\%$ \\
\hline \multicolumn{7}{|c|}{ Se cumple con motivar suficientemente la aplicación de la suspensión de la ejecución de la pena } \\
\hline Si & 2 & 100 & 1 & 20 & 23 & 15 \\
\hline No & 0 & 0 & 4 & 80 & 135 & 85 \\
\hline Total & 2 & 100 & 5 & 100 & 158 & 100 \\
\hline \multicolumn{7}{|c|}{$\begin{array}{l}\text { Las reglas de conducta impuesta en las medidas suspensión de la ejecución de la pena son adecuadas para } \\
\text { garantizar la resocialización del condenado. }\end{array}$} \\
\hline Si & 0 & 0 & 1 & 20 & 19 & 12 \\
\hline No & 2 & 100 & 4 & 80 & 139 & 88 \\
\hline Total & 2 & 100 & 5 & 100 & 158 & 100 \\
\hline \multicolumn{7}{|c|}{$\begin{array}{l}\text { Se cumple con implementar medidas resocializadoras y rehabilitadoras para garantizar la resocialización del } \\
\text { condenado. }\end{array}$} \\
\hline Si & 0 & 0 & 0 & 0 & 18 & 11 \\
\hline No & 2 & 100 & 5 & 100 & 140 & 89 \\
\hline Total & 2 & 100 & 5 & 100 & 158 & 100 \\
\hline \multicolumn{7}{|c|}{ En los casos de suspensión de la ejecución de la pena, los condenados corrigen su conducta. } \\
\hline Si & 0 & 0 & 0 & 0 & 28 & 18 \\
\hline No & 2 & 100 & 5 & 100 & 130 & 82 \\
\hline Total & 2 & 100 & 5 & 100 & 158 & 100 \\
\hline \multicolumn{7}{|c|}{$\begin{array}{l}\text { Efectos de la amonestación, prórroga o revocación, ante el incumplimiento de las reglas de conducta en la } \\
\text { resocialización del condenado: }\end{array}$} \\
\hline Positivo & 0 & 0 & 1 & 20 & 28 & 18 \\
\hline Negativo & 2 & 100 & 4 & 80 & 130 & 82 \\
\hline Total & 2 & 100 & 5 & 100 & 158 & 100 \\
\hline \multicolumn{7}{|c|}{$\begin{array}{l}\text { En los casos de suspensión de la ejecución de la pena, los condenados reinciden en el hecho punible, haciendo } \\
\text { ineficaz su resocialización. }\end{array}$} \\
\hline Si & 2 & 100 & 5 & 100 & 129 & 82 \\
\hline No & 0 & 0 & 0 & 0 & 29 & 18 \\
\hline Total & 2 & 100 & 5 & 100 & 158 & 100 \\
\hline \multicolumn{7}{|c|}{ La pena privativa de libertad con el carácter de suspendida cumple su función resocializadora. } \\
\hline Si & 0 & 0 & 0 & 0 & 22 & 14 \\
\hline No & 2 & 100 & 5 & 100 & 136 & 86 \\
\hline Total & 2 & 100 & 5 & 100 & 158 & 100 \\
\hline \multicolumn{7}{|c|}{ La suspensión de la pena privativa de libertad debe desaparecer y dar paso a otras penas alternativas. } \\
\hline Si & 2 & 100 & 5 & 100 & 145 & 92 \\
\hline No & 0 & 0 & 0 & 0 & 13 & 8 \\
\hline Total & 2 & 100 & 5 & 100 & 158 & 100 \\
\hline
\end{tabular}

El 100\% de los jueces encuestados señalan que los efectos de la amonestación, prórroga o revocación, ante el incumplimiento de las reglas de conducta en la resocialización del condenado, son negativos. El $80 \%$ de los fiscales encuestados señalan que, son negativos; y, el $20 \%$ señala lo contrario. El $82 \%$ de los abogados encuestados señalan que, son negativos; y, el $18 \%$ señala lo contrario. Los resultados nos permiten determinar que, los efectos de la amonestación, prórroga o revocación, ante el incumplimiento de las reglas de conducta en la resocialización del condenado, 
son negativos, por cuanto no inciden en su resocialización, producto de ello es la reincidencia del condenado.

Para el $100 \%$ de los jueces encuestados, en los casos de suspensión de la ejecución de la pena, los condenados reinciden en el hecho punible, haciendo ineficaz su resocialización. El $100 \%$ de los fiscales encuestados señalan que, en los casos de suspensión de la ejecución de la pena, los condenados reinciden en el hecho punible, haciendo ineficaz su resocialización. El $82 \%$ de los abogados encuestados señalan que, en los casos de suspensión de la ejecución de la pena, los condenados reinciden en el hecho punible, haciendo ineficaz su resocialización; y, el $18 \%$ dice lo contario. Los resultados nos permiten determinar que, en los casos de suspensión de la ejecución de la pena, los condenados reinciden en el hecho punible, haciendo ineficaz su resocialización.

Igualmente, la totalidad de jueces encuestados señalan que, la pena privativa de libertad con el carácter de suspendida cumple su función resocializadora. El 100\% de los fiscales encuestados señalan que, la pena privativa de libertad con el carácter de suspendida cumple su función resocializadora. El $86 \%$ de los abogados encuestados señalan que, la pena privativa de libertad con el carácter de suspendida cumple su función resocializadora; y, el 14\% manifiesta lo contrario. Los resultados nos permiten determinar que, la pena privativa de libertad con el carácter de suspendida cumple su función resocializadora.

El 100\% de los jueces encuestados señalan que, la suspensión de la pena privativa de libertad debe desaparecer y dar paso a otras penas alternativas. El $100 \%$ de los fiscales encuestados señalan que, la suspensión de la pena privativa de libertad debe desaparecer y dar paso a otras penas alternativas. El 92\% de los abogados encuestados señalan que, la suspensión de la pena privativa de libertad debe desaparecer y dar paso a otras penas alternativas, y el $8 \%$ lo contrario. Los resultados nos permiten determinar que, la suspensión de la pena privativa de libertad debe desaparecer y dar paso a otras penas alternativas.

\section{Análisis e interpretación de resultados de la entrevista aplicada}

Los resultados de la entrevista aplicada a los magistrados de la Corte Superior de Justicia de Tacna: Gonzales, Ordoño, y Alvarado, cuyas manifestaciones se muestran a continuación:

1. ¿Considera se han establecido los requisitos adecuados para aplicar la suspensión de la ejecución de la pena? Fundamente.

No, porque el legislador no hizo un estudio, ni análisis comparativo de la política criminal en nuestro país; por tanto, los requisitos para la aplicación de la suspensión de la ejecución de la pena resultan ser genéricas, siendo los requisitos muy formales y abiertos. Así por ejemplo se hace referencia a la naturaleza y modalidad de hechos punibles, dejando un marco amplio e impreciso para su concreción.

2. ¿Considera que las reglas de conducta impuesta en las medidas de suspensión de la ejecución de la pena son adecuadas para garantizar la resocialización del condenado? Fundamente.

No, porque existe implicancia entre suspender la ejecución de la pena bajo la premisa de que el agente no volverá a cometer delito, y la fijación de reglas, las cuales no tendrían propósito, por cuanto se supone que no se volverá a cometer delito.

Las reglas impuestas no son impuestas en función del agente, las cuales no la resocializan muy por el contrario estos continúan delinquiendo. Estas tendrían que ser integradas o complementadas para su fijación.

3. ¿Considera que se cumple en controlar las reglas de conducta impuesta en las medidas suspensión de la ejecución de la pena? Fundamente.

No se cumplen, a excepción de la concurrencia del juzgado, encontrando justificación en la excesiva carga procesal de jueces y fiscales y la falta de recursos para su control. 
4. ¿Qué efectos considera tiene la amonestación, prórroga o revocación, ante el incumplimiento de las reglas de conducta en la resocialización del condenado?

El artículo 59a del Código Penal señala que en caso de que durante el periodo de suspensión el condenado no cumpliera con las reglas de conducta impuestas o fuera condenado por otro delito, el juez podría, según los casos: 1) amonestar al infractor, 2) prorrogar el periodo de suspensión hasta la mitad del plazo inicialmente fijado, o 3) revocar la suspensión de la pena. Por tanto, es facultad legal del juzgador el adoptar cualquiera de estas medidas ante un eventual incumplimiento de las normas de conducta fijadas. La reincidencia presentada ante el incumplimiento de estas medidas hace prever la ineficacia de su aplicación en la resocialización del condenado, por cuanto en la mayoría de los casos se aplica la revocatoria de la pena, por lo tanto, el condenado tiene que ser internado en el centro penitenciario, en consecuencia, bajo estos hechos, dichas medidas no tienen un efecto positivo en la resocialización del condenado.

5. ¿Considera que se cumple con implementar medidas resocializadoras y rehabilitadoras para garantizar la resocialización del condenado? Fundamente.

No, por cuanto el Estado se muestra indiferente y no atiende este aspecto, el cual es de suma importancia para garantizar el desarrollo de la sociedad y sobre todo la resocialización del condenado.

6. ¿Desde su rol, considera que la pena privativa de libertad con el carácter de suspendida cumple su función resocializadora? Fundamente.

No, porque se observa la reincidencia en los delitos cometidos, y en consecuencia la función resocializadora de la pena es ineficaz.

7. ¿Desde su rol, considera que la suspensión de la pena privativa de libertad debe desaparecer y dar paso a otras penas alternativas? Fundamente.

$\mathrm{Si}$, por cuanto existen otras penas como son los trabajos comunitarios, la pena de multa, limitación de días libres.

Cuando se impone la pena suspendida es porque se considera que el sentenciado no va a cometer nuevo delito, por tanto, esa regla de conducta no resulta ser la adecuada en ningún caso.

\section{Comprobación de hipótesis}

- $\mathrm{H}_{0}$ : Probablemente la ineficaz aplicación de la suspensión de la ejecución de la pena establecida en el Código Penal no incide en la resocialización del condenado.

- $\mathrm{H}_{1}$ : Probablemente la ineficaz aplicación de la suspensión de la ejecución de la pena establecida en el Código Penal incide en la resocialización del condenado.

\begin{tabular}{|c|c|c|c|c|}
\hline & & \multicolumn{3}{|c|}{ Resocialización del condenado } \\
\hline & & Reeducación & Rehabilitación & Reincorporación \\
\hline \multirow{5}{*}{$\begin{array}{l}\text { Suspensión de la } \\
\text { ejecución de la } \\
\text { pena }\end{array}$} & Requisitos & $x_{1}^{2}=93,103$ & $X_{1}^{2}=155,000$ & $x_{1}^{2}=36,456$ \\
\hline & & Sig. asintótica $=, 000$ & Sig. asintótica $=, 000$ & Sig. asintótica $=, 000$ \\
\hline & Reglas & $x_{1}^{2}=145,770$ & $X_{1}^{2}=98,998$ & $x_{1}^{2}=110,000$ \\
\hline & conducta & Sig. asintótica $=, 000$ & Sig. asintótica $=, 000$ & Sig. asintótica $=, 000$ \\
\hline & $\begin{array}{l}\text { Medidas } \\
\text { impuestas }\end{array}$ & $\begin{array}{l}X_{1}^{2}=110,161 \\
\text { Sig asintótica }=000\end{array}$ & $\begin{array}{l}X_{1}^{2}=130,999 \\
\text { Sig asintótica }=000\end{array}$ & $X_{1}^{2}=117,136$ \\
\hline
\end{tabular}

Del cuadro anterior se detalla la prueba de chi-cuadrado se verifica que en todos los casos las Sig. Asintótica son menores que el nivel de significación < 0,05; por lo que se puede rechazar la hipótesis $\mathrm{H}_{0}$, y se concluye que: Probablemente la ineficaz aplicación de la suspensión de la ejecución de la pena establecida en el Código Penal incide en la resocialización del condenado. 
Asimismo, estos resultados coinciden con los resultados de la ficha de análisis de los casos de la suspensión de la ejecución de la pena establecida en el Código Penal; y, los resultados de las entrevistas a los magistrados.

\section{DISCUSIÓN}

La presente investigación tuvo como objetivo analizar en qué medida la ineficaz aplicación de la suspensión de la ejecución de la pena establecida en el Código Penal incide en la resocialización del condenado, Tacna 2015-2018. Los resultados nos permiten inferir que: Probablemente la ineficaz aplicación de la suspensión de la ejecución de la pena establecida en el Código Penal incide en la resocialización del condenado, Tacna 2015-2018.

Estos resultados guardan relación con el estudio de Briceño, (2018). Reforma de una pena efectiva por una suspendida y el proceso de resocialización del reo -2da sala penal Lima Norte, 2017, quien señala que, la reforma de la pena privativa de libertad, suspendida en su ejecución no beneficia en la resocialización del sujeto penado al cual se le otorgó dicho beneficio, en las sentencias condenatorias por delitos contra el patrimonio-robo agravado y agresión física en la sala Penal de Lima Norte 2017.

Asimismo, los resultados del presente estudio también guardan relación con el estudio de: Salazar (2016) En el Juzgado de Instrucción Preparatoria de Moyobamba, el control de cumplimiento del Código de Conducta y la revocación de la suspensión de la pena de prisión arrojó que los resultados descriptivos arrojaron que el 52,94\% de ellos fueron condenados a suspensión de la pena en el Juzgado de Instrucción Preparatoria para hacer cumplir las normas de conducta, mientras que $47.06 \%$ no sigue las reglas de conducta. Por tanto, entre las penas privativas de libertad por suspensión, la mayor infracción a la regla de conducta es la reparación del daño causado por el delito, que representa el $25,00 \%$, incluyendo el pago de indemnización civil a la víctima. Por otro lado, considerando la condición de Moyobamba o la falta de reglas de conducta, el $57.65 \%$ de las sentencias fueron revocadas en la sentencia suspendida del Juzgado de Instrucción Preparatoria de Moyobamba. Finalmente, Merino (2014). En 2010, la condena del Tribunal Único de la provincia de Trujillo por delitos contra la propiedad suspendió la ejecución de la pena y dejó de tomar medidas preventivas generales activas, lo que indicó que se suspendió la ejecución de la pena. La pena privativa de libertad incide en la finalidad de la prevención activa e integral, pues se observa que, en el caso de la universalidad no prevista por la ley, y en el caso de incumplimiento de los requisitos de la Ley Penal, se han implementado sentencias suspendidas, el contexto de excepciones y cómo esto cambia el efecto comunicativo que debe cumplir la pena.

\section{CONCLUSIONES}

Los antecedentes citados nos permiten corroborar la hipótesis de investigación: Probablemente la ineficaz aplicación de la suspensión de la ejecución de la pena establecida en el Código Penal incide en la resocialización del condenado, Tacna 2015-2018; ya que en la mayoría de los casos se incumplen las reglas de conducta, los requisitos no son los adecuados; y las medidas ante su incumplimiento tales como: amonestación, prorroga y revocatoria no tienen efectos positivos en la resocialización del condenado.

\section{RECOMENDACIONES}

Los operadores del derecho deben realizar una evaluación de la eficacia de la aplicación de la suspensión de la ejecución del pena y presentar una propuesta legislativa donde se deroguen los artículos $57^{\circ}$ al $61^{\circ}$ del Código Penal; para ello el Juez deberá optar en su lugar, por las medidas alternativas a la pena privativa de libertad como son: las penas restrictivas de libertad: expulsión y 
expatriación; y las limitativas de derechos: prestación de servicios a la comunidad, limitación de días libres e inhabilitación y finalmente la imposición de pena de multa y se aplicará exclusivamente a los delitos cuya pena a imponerse sea inferior a los cuatros años de pena privativa de libertad, y el juez de ejecución penal será el encargado de implementar los mecanismos y estrategias apropiadas para el cumplimiento de tales penas.

\section{REFERENCIAS BIBLIOGRÁFICAS}

Arroyo, R. (2017). Suspensión de la ejecución de la pena privativa de libertad dispuesta por sentencia apelada en el código penal militar policial. Lima: Universidad César Vallejo.

Briceño, A. (2018). Reforma de una pena efectiva por una suspendida y el proceso de resocialización del reo -2da sala penal Lima Norte, 2017. Lima: Universidad César Vallejo.

Chávez, D. (2017). El trabajo comunitario como alternativa para la conversión de las penas en el delito de omisión de asistencia familiar para los fines de resocialización del imputado. Cusco: Universidad Andina Cusco.

Código Penal, 1. (1991). Título IV De las Medidas de Seguridad. Lima: Grijel.

Código Penal. (2006). Jurisprudencia Penal del tribunal Constitucional. Lima: Jurista editores.

Constitución Política del Perú. (1993). Constitución Política del Perú Comentada Art. 139o numeral 22. Lima: Editores.

Exp.0957-2003 HC/TC. (2003). Jurisprudencia Penal del Tribunal Constitucional. Arequipa: Gaceta Jurídica.

Franco, M. (2017). La suspensión dela ejecución de las penas privativas de libertad en el Código penal español: cuestiones controvertidas a las que se enfrentan los tribunales de justicia en su aplicación. Bilbao: Universidad del País Vasco.

Garcia Cavero, P. (2005). Fines de la pena y de la medida de seguridad Art. IX del Titulo Preliminar del Codigo Penal. En G. Jurídica, Código Penal Comentado (pág. 212). Lima: Gaceta Jurídica S.A.

Garcia Cavero, P. (2005). Titulo IX Fines de la Pena. Lima: GRIJLEY.

Gonzales, A. (2018). Proceso de resocialización y su incidencia en los internos condenados por robo agravado en el distrito Judicial de Lima Norte, 2013 - 2017. Lima: Universidad César Vallejo.

Hernández, N. (2015). La Resocialización como fín de la Pena una frustración en el sistema penitenciario y carcelario colombiano. Bogotá: Universidad Libre y Universidad de los Andes.

Mejia. (2005). Fundamentos del derecho penal. En Mejia, Derecho Penal (pág. p.32). Lima: juristas editores.

Merino, C. (2014). La suspensión de la ejecución de la pena privativa de libertad y fín de prevención general positiva en las sentencias condenatorias por delitos contra el patrimonio en los juzgados unipersonales de la provincia de Trujillo en el año 2010. Trujillo: Universidad Privada Antenor Orrego.

Salazar, D. (2016). El control del cumplimiento de las reglas de conducta y la revocación de la suspensión de la pena en los sentenciados a pena privativa de libertad suspendida en su ejecución en los juzgados de investigación preparatoria de Moyobamba del año 2015. Lima: Universidad César Vallejo.

Tribunal de Casación. (1999). La Legislación a favor de la educación de los detenidos. La Plata: Astrea. Tribunal de Casación. (2000). La Legislación a favor de la educación de los detenidos. La Plata: Astrea. Villabella, C. (2015). Los métodos en la investigación jurídica. México: UNAM. 